FACTA UNIVERSITATIS

Series: Mechanical Engineering Vol. 18, N 2, 2020, pp. 229 - 244

https://doi.org/10.22190/FUME200603024R

Original scientific paper

\title{
EFFECTS OF VOLUME OF CARBON NANOTUBES ON THE ANGLED BALLISTIC IMPACT FOR CARBON KEVLAR HYBRID FABRICS
}

\section{Elias Randjbaran ${ }^{1}$, Dayang L. Majid ${ }^{1}$, Rizal Zahari ${ }^{1,2}$, Mohamed T. H. Sultan ${ }^{1}$, Norkhairunnisa Mazlan ${ }^{1}$}

${ }^{1}$ Department of Aerospace Engineering, Faculty of Engineering, Serdang, Selangor, Malaysia

${ }^{2}$ Systems Engineering Department, Military Technological College, Muscat, Sultanate of Oman

\begin{abstract}
Investigations of the angled ballistic impact behavior on Carbon Kevlar ${ }^{\circledR}$ Hybrid fabrics with assorted volumes of carbon nanotubes (CNTs) into epoxy are presented. The ballistic impact behavior of the epoxy composites with/without CNTs is compared. Individual impact studies are conducted on the composite plate made-up of Carbon Kevlar Hybrid fabrics with diverse volumes of CNTs. The plate was fabricated with eight layers of equal thickness arranged in different percentages of CNTs. A conical steel projectile is considered for a high velocity impact. The projectile is placed very close to the plate, at the centre and impacted with sundry speeds. The variation of the kinetic energy, the increase in the internal energy of the laminate and the decrease in the velocity of the projectile with disparate angles are also studied. Based on the results, the percentage of CNTs for the ballistic impact of each angle is suggested. The solution is based on the target material properties at high ballistic impact resistance, the inclined impact and the CNT volumes. Using the ballistic limit velocity, contact duration at ballistic limit, surface thickness of target and the size of the damaged zone are predicted for fabric composites.
\end{abstract}

Key Words: Carbon Nanotubes, Oblique Impact, Ballistic Impact, Kevlar Fiber, Carbon Fiber

Received June 03, 2020 / Accepted July 18, 2020

Corresponding author: Elias Randjbaran

Department of Aerospace Engineering, Faculty of Engineering 43400 UPM, Serdang, Selangor, Malaysia E-mail: Elias@gmx.co.uk 


\section{INTRODUCTION}

Reinforcing composite panels affects their mechanical properties as well as their weight, which are two crucial considerations for a wide range of applications such as the process of responsibility of naval vessels designers, armored vehicle designers and manufacturers, aircraft designers, etc. [1-6]. Due to effective behavior and safe performance, the use of $\mathrm{CNT} /$ Epoxy composites as materials for structural design of vehicles and other constructions has led to the requirements of sustaining them. A special attention ought to be paid to the commercial aircraft structures that must be lightweight and divulge exceptional impact resistance properties in order to meet growing demands in this industry. Peculiarly, a body of commercial aircrafts is mostly made of composite materials and metals [5-9]. Due to weight issue as well as to an increasing role of saving energy in the modern life, weight deduction can be one of the major challenges of the commercial aircraft designer despite retaining the quality and guarantee for the safety [6-8 \&10]. Therefore, some parts of the body can be replaced with laminate composite materials [8-10]. Moreover, the most economical and conventional fabric is glass fiber, despite the fact that the glass fiber use has a lot of drawbacks, e.g. consistently triggered physical problems, health issues and respiratory irritations, allowing for air flow, trap allergens, while moisture can get trapped inside the fiberglass insulation material and thus become a bedding material for pests [10-12]. Consequently, modern attempts at circumventing the drawbacks of using glass fiber, which can be inevitable, and replacing it with Kevlar and carbon fiber as well as adding CNT into resin epoxy can be recommended. Numerous studies regarding the ways of revitalizing the use of natural fibers have been published and the trend of applying natural fibers is increasing, but technically, in industrial scales, none of manufacturers has used or even recommended them [13-15]. Eventually safe, durable materials, but expensive Kevlar/ Carbon Fiber Hybrid Fabrics with CNT epoxy resin are studied in the current research to normal and oblique impact resistance. Carbon fibers, despite their high price, are predominantly used for ballistic protection under rifle bullet threats [15-18]. Although commercial monolithic carbon fiber plates could be manufactured to a large thickness, they may not meet the design needs for certain thickness and multiple thinner plates, which are used to meet design specifications. In addition, multi-layer plates can provide flexibility to users in terms of mobility and maintenance [17-19]. For this reason, most experimental studies as well as those in the published works relating to the ballistic performance of carbon fiber plates focus on replacing monolithic plates with layered plates of the same thickness. The chief goal of these experiments is to reduce the overall weights of armor plates while maintaining the same ballistic protection as epoxy-CNT carbon-Kevlar composite plates [18-21].

Although some other fibers including asbestos or wood or paper have been sporadically used, the fiber-reinforced polymer (FRP) is made of a resin matrix reinforced with fibers that can be conventionally glass, carbon, or Kevlar. [22-24]. Since the fibers are used to support the load by providing excellent strength to the structure, the resin serves as matrix material to transfer the load to the reinforcement and then to hold and protect the fibers [25-28]. The FRP composites have a variety of superior properties such as a high strength-to-weight ratio; they could provide high dimensional stability, excellent fatigue, light-weight engineering solutions, corrosion, wear resistance, etc. [29-33]. Because of these attractive properties, the FRP composites have been widely used for numerous applications such as aerospace and 
commercial aircrafts, automobile, sports goods, robot arms, chemical containers, and fishing rods [34-36]. Especially in commercial aircraft industry, the FRP composites have been in a remarkably increasing demand. For example, the innovative FRP composite fuselage has been widely applied in Airbus A350 aircraft, and about 53\% of the materials in A350 airframe are made of composites. The FRP composite part fabrication with a shorter cycle time is desired to meet a high demand for FRP composites, although they have a higher production cost [37-39].

On another note, the commercial aircraft structures are exposed to bird strike events causing serious damages, which usually occur in flight or on take-off and include bird strikes or impact by hail, tyre rubber, engine fragments or runway debris. Ballistic impact scenarios are low mass with often ballistic impact speeds transpiring from ammunitions with implementation to security protection structures. A few papers were published on this expensive and sometimes-lethal flying risk, though annual damages from bird and bat collisions with aircraft were estimated at and up to $\$ 1.2$ billion in commercial aviation worldwide; that is why so many councils are dedicated to the problem at numerous conferences. By providing a comprehensive guide to preventing and minimizing damage caused by a bird strike on the aircraft, the researchers attempt to bridge the current gap. The Fact Sheet of the Federal Aviation Administration's (FAA) about Wildlife Hazard Mitigation Programme on 9th January, 2019, declared, from 1990 to 2017, the reported costs for civil aircraft in USA totalled $\$ 765$ million for the 28 -year period as well as costs are adjusted to the reported strikes in which costs were not provided; regarding the estimated number of strikes that were not reported, losses could be as high as $\$ 500$ million per year. Moreover, 311 human injuries are attributed to wildlife strikes with US civil aircraft. In addition, 287 human fatalities are attributed to wildlife strikes globally (Fig. 1). Hence, advance material development and analyses pertaining to the ballistic impact strikes present a continuous challenge to the composites' community. In this work, the ballistic impacts are simulated for so-called bird strike impacts.

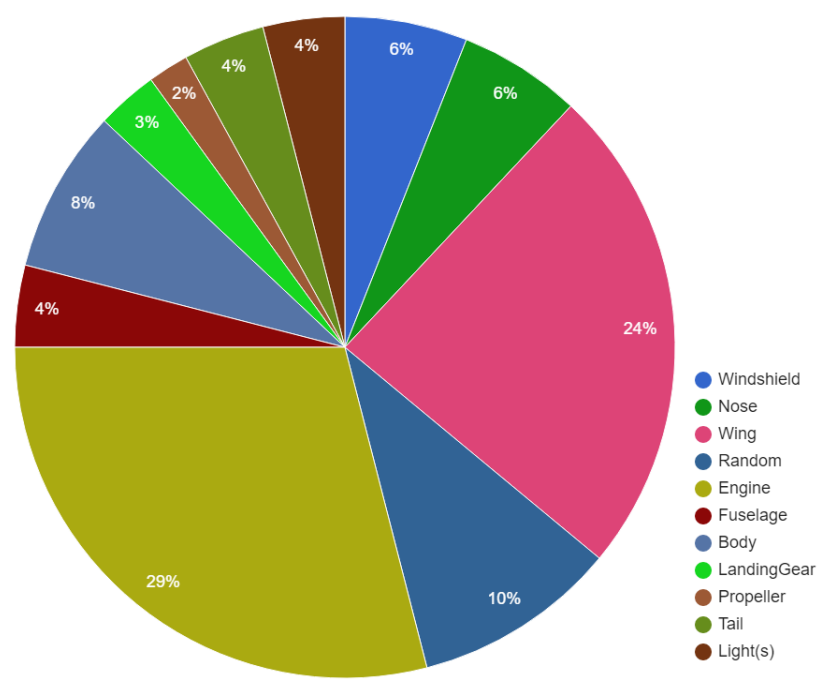

Fig. 1 Locations of bird-strike damage (Boeing report) [38] 


\section{MethodOLOGY}

In this paper, the carbon/Kevlar reinforced epoxy composite with CNT fillers of a varying loading ratio were fabricated; they underwent ballistic impact testing and their responses were analyzed.

\subsection{Fabrication}

For the absorbing nanostructured composites processing, carbon nanotubes were dispersed in an epoxy resin matrix. The carbon nanotubes (type CM-95/MWCNT) were acquired from ILJIN NANOTECH co. ltd. (Seoul, South Korea). According to the manufacturer, this MWCNT has size of 0.01-0.015 $\mu \mathrm{m}$ of diameter and 10-20 $\mu \mathrm{m}$ of length. As shown in Fig. 2, CNT-epoxy composites sample were fabricated using CNT, a dispersing agent BYK 9077, and Araldite 2016. CNTs and BYK 9077 with ethanol were blended for five minutes; soon after it there followed sonication for an hour at fixed output power of 25 Watts. The mixture was added to the resin and stirred for 10 minutes with a high shear blending homogenizer at 3500 RPM, followed by 45 minutes sonication treatment. The blend was then placed in a vacuum degassing oven and remained at room temperature $\left(25^{\circ} \mathrm{C}\right)$ for 48 hours under $1 \mathrm{Bar}$, followed by 24 hours under $1 \mathrm{Bar}$ at $80^{\circ} \mathrm{C}$ for degassing process. An open mould process in which components or successive plies of reinforcing material or resin-impregnated reinforcements are applied to the mould and the composite is built up and worked by hand. Curing is normally conducted at ambient temperatures, but may be accelerated by heating, if desired. In addition, the hand lay-up process produces the largest amount of reinforced composite products.

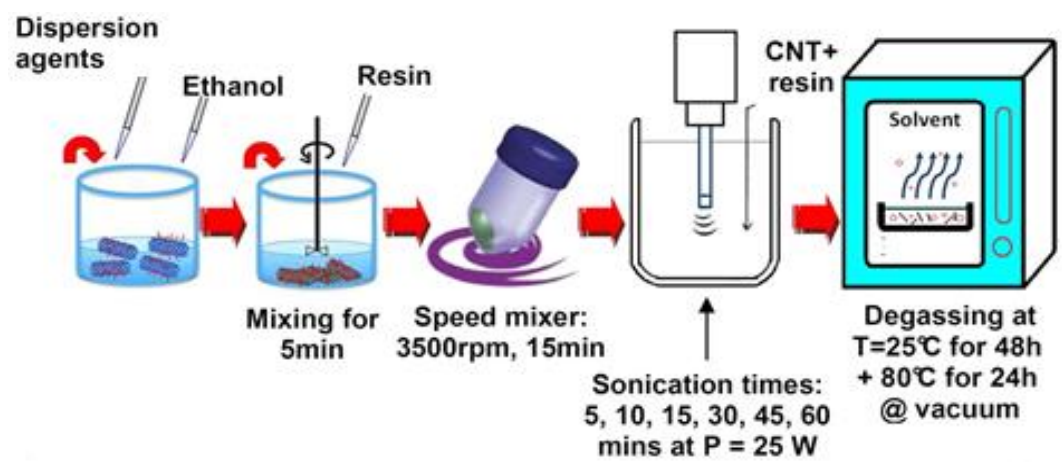

Fig. 2 Schematic diagram of the fabrication protocol for CNT-epoxy composites

\subsection{Ballistic Impact Tests}

Fig. 3 displays a schematic diagram that is in accordance to the NIJ 0108.01 Standard produced by the National Institute of Justice (NIJ) and the detailed procedures for ballistic protection certification and testing [41]. The gas gun tunnel facility utilized in this work was developed at the Department of Aerospace Engineering, University Putra Malaysia (UPM) as reported here [44]. The noted standard is focused on shields, blankets, and visors. Compressed (pressurized) Nitrogen gas is used as a working fluid. The reason for this is that nitrogen gas has the advantages of being colorless, odorless, 
tasteless, and non-toxic. Moreover, it is commercially available and as a chemical element it contains a high thermal conductivity. Its lightness as well as its inferior density in comparison to atmospheric (due to a lower mass of the nitrogen particles) air is another criterion for its selection to carry out the experiment. Another advantage of nitrogen gas lies in its low density which facilitates the movement of the bullet as the sound waves travel faster in a less dense material than in a denser one [40-44].

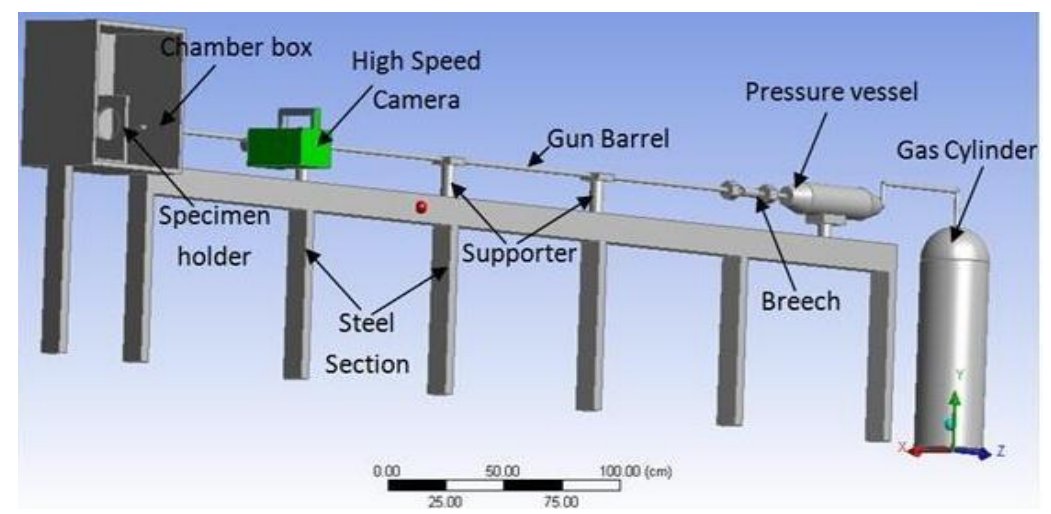

Fig. 3 Schematic of ballistic test setup following the NIJ Standard [44]

Fig. 4 illustrates inclined target, which can be rotated from 90 to 140 degrees with an angle indicator, all made of stainless steel. This bullet trap features a spent bullet depository and ballistic rubber front panel, $12.7 \mathrm{~mm}$ thick with self-healing properties. The ballistic front panel can slow down the rounds, minimize the impact noise, and lead dust generation [43-46].
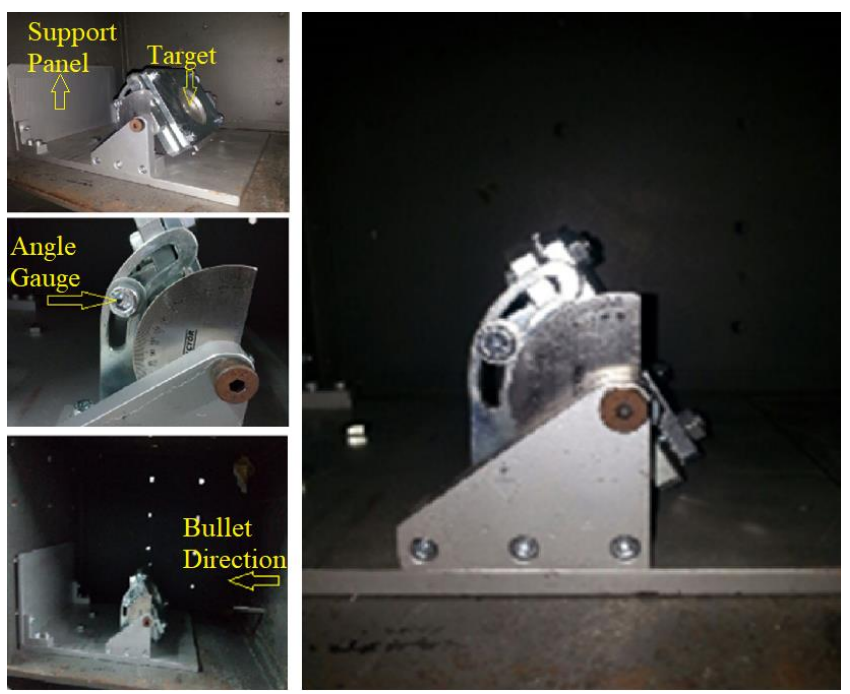

Fig. 4 Set-up for inclined target 
The energy that must be dissipated in the collision is approximately relative kinetic energy $\mathrm{E}_{\mathrm{k}}$ of the bird, defined by:

$$
\mathrm{E}_{\mathrm{k}}=0.5 \mathrm{mv}^{2} \text {, }
$$

where $\mathrm{m}$ is the mass of the bird and $\mathrm{v}$ is the relative velocity (the difference of the velocities of the bird and the plane, resulting in a lower absolute value if they are flying in the same direction and a higher absolute value if they are flying in opposite directions) [46-48].

The ballistic limit formula for armor TM5-855-1 by [43]:

$$
\mathrm{V}_{50}=3922 \mathrm{~W}_{\mathrm{T}}^{-0.5} \mathrm{~d}^{0.7}\left(\mathrm{e}_{\mathrm{h}} \sec (\theta)\right)^{0.8},
$$

where $V_{50}$ is the ballistic limit velocity in fps, $d$ is the caliber of the projectile, in inches, $e_{h}$ is the thickness of the homogeneous armor, $\theta$ is the angle of obliquity, $W_{T}$ is the weight of the projectile (in lbs).

In Eq. (2), the theoretical ballistic limit is investigated but the coefficient of materials is not considered as a correlation. Moreover, in this equation one velocity is only pointed out due to the fact that the initial and final speeds are the ballistic limit.

$\mathrm{V}_{50}$ ballistic limit is the means of comparing the ultimate performance of armor materials. $\mathrm{V}_{50}$ ballistic limit is the velocity at which a specific projectile (bullet) is expected to penetrate the armor half of the time. The ballistic limit of armor is most frequently conducted using the procedures of TM5-855-1. In other words, a given projectile cannot generally pierce a given target when the projectile velocity is lower than the ballistic limit [41-43].

Fig. 5 clearly illustrate that the thicknesses of plates A and B are $30 \mathrm{~mm}$ and $23 \mathrm{~mm}$. On one hand, it means plate $\mathrm{A}$ is approximately $30 \%$ thicker than $\mathrm{B}$. On the other hand, by increasing the angle up to 45 degrees, the effective thickness is $32.5 \mathrm{~mm}$. It means that B is not only definitely lighter but it is also about $8.34 \%$ thicker than A. Triangular profile inserts are enforced to have uniform area density from angled plate (in B) and the thickness of normal plate (in B) must be diminished to compensate for the weight of these impacts. Furthermore, an illustration of proof of angled plate proposes less weight benefit while protecting a certain width, which is a comparison of a vertical slab of plate on the left and a section of plate sloped at an angle of 45 degrees on the right and the horizontal distance

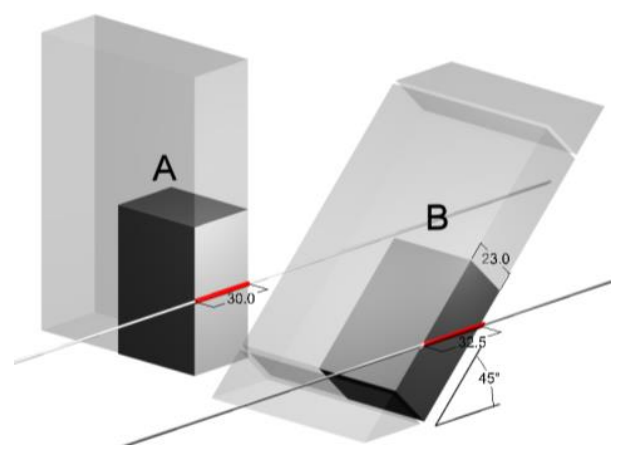

Fig. 5 Thicknesses of right and inclined angle [12] 
via the plate is the same. However, the normal thickness of the sloped plate is lower. Therefore, the actual cross-sectional area of the armor, and hence its mass, is the same in each case. Due to mass, the normal will have to decrease if the angles are elevated.

$$
\mathrm{T}_{\mathrm{I}}=\mathrm{T}_{\mathrm{N}} \cdot \sec (\alpha)
$$

where $\alpha$ is the angle of the sloped armor plate from the vertical, $\mathrm{T}_{\mathrm{N}}$ is the normal thickness, $\mathrm{T}_{\mathrm{I}}$ is the inclined thickness.

For instance, as the second of $60^{\circ}$ is 2 , the armor sloped sixty degrees back from the vertical presents to a projectile travelling horizontally a line-of-sight thickness $\left(\mathrm{T}_{\mathrm{I}}\right)$ twice armor's normal thickness $\left(\mathrm{T}_{\mathrm{N}}\right)$.

\section{RESULTS AND DISCUSSION}

\subsection{Morphology}

Fig. 6 shows pure multi-walled carbon nanotubes (MWCNTs). Furthermore, Figs. 7a and $7 \mathrm{~b}$ show the surface morphologies captured from specimens coated with the solutions of the active layer (Fig. 7a) and not well-dispersed (Fig. 7b). The SEM images clearly illustrate that the dispersion of the epoxy-CNTs in the matrix is not well for the nanocomposite formed, which favors CNT agglomeration and entanglement that form various CNT clusters due to an excessive amount of CNT (more than 0.3\%). On the other hand, the well-dispersed epoxy-CNTs is observed for the composite prepared (Fig. 6): this can be ascribed to the monomers polymerized on the surface of the epoxy-CNTs; this inhibits $\pi-\pi$ interaction of the nanotubes and thereby decreases agglomeration. Moreover, the well-dispersed epoxy-CNT means there is a continuous percolation path for free charge carriers and eventual collection at the impact resistance thereby improving cell performance in mechanics of impact.
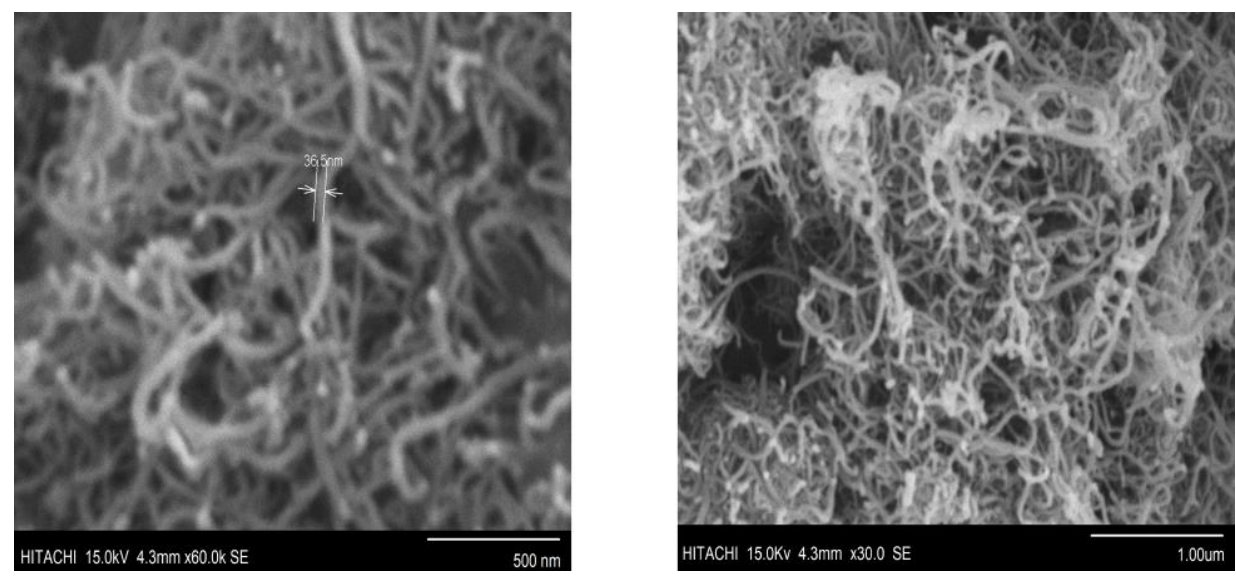

Fig. 6 MWCNTs magnified by SEM (500nm and $1.00 \mu \mathrm{m})$ 
Fig. 7 shows the images obtained by SEM of the materials processed observing in Fig. 6 that the nanotubes are imperfectly distributed and the presence of clusters in island ( $0.3 \%$ CNT/epoxy composite) in composite. However, within the island the CNTs are dispersed indicating the formation of an interconnected network. According to the SEM fracture surface images showing tested composite laminates in Fig. 7, it can be seen that the fibers are covered with epoxy, stipulating magnificent adhesion between the resin and the fibers with the appearance of CNTs, which could be observed equally on both the fiber surfaces and the connected irrefutably interfacial regions between the matrix and the fibers. Furthermore, it can contribute immensely to enhanced stress transfer compared to the composites based on neat epoxy resins. The excellently-dispersed CNT network within these fabric laminates can be used for damage sensing presently by monitoring how mechanical resistivity transforms from progressive cracking showing the crosssectional areas of composite reference specimen and hybrid CNT/epoxy specimen after impact tests, respectively, where very clear inter-laminar impact failures are observed.

The type and amount of aggregation of CNT structures are evidently determined by rigidity of nanotubes and whether their diameters are thin enough to allow indubitably their buckling and self-aggregation into low-density, particle-like, intertwined, and coiled assemblages. Moreover, the production technique can unquestionably impact the sorts of cluster structure and whether it is stabilized incontrovertibly by adequate agglomeration or some sort of inter-tubular aggregation (physical entanglement). Consequently, contingent on these characteristics, agglomerate structures of nanotubes can appreciably differ from thin-walled CNT to thick-walled, rigid CNT; examined, they exhibit a strong tendency to aggregate into microscopic bundles (clusters) demonstrably and in turn agglomerate loosely into small clusters that are substantially visible; forming CNT agglomeration exists inevitably in all CNT-epoxy composites. Conceptually, presented as spherical assemblages of intertwined tubes verified by image interpretation from the samples were purposefully assumed as agglomerates (in Fig. 7).
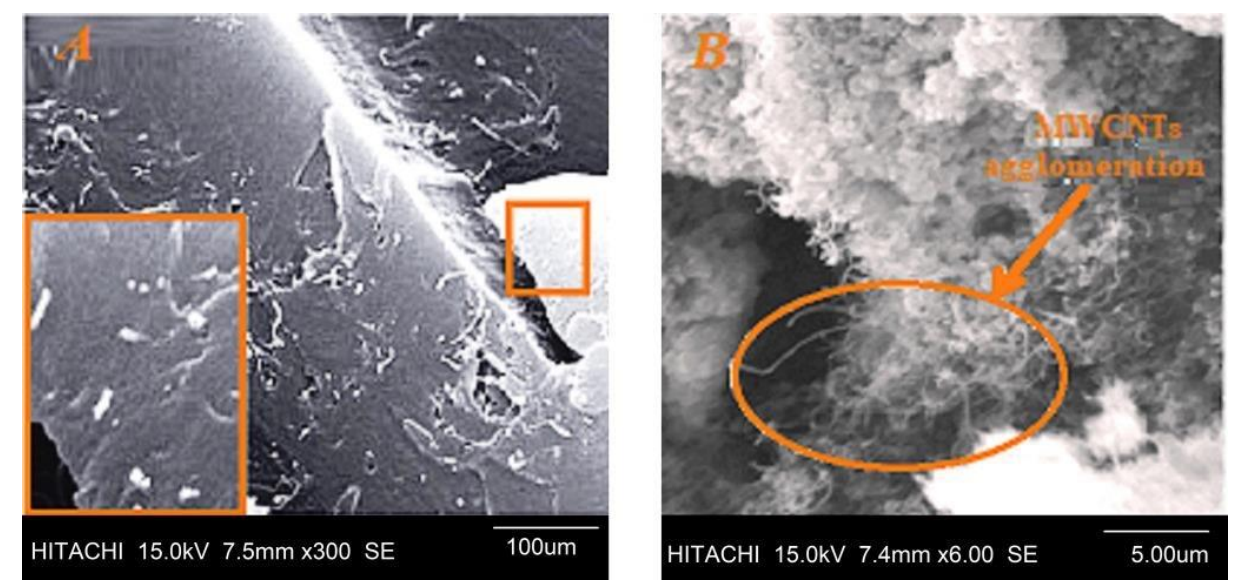

Fig. 7 Damaged samples A) dispersed $0.3 \%$ CNT on surface and B) $1.5 \%$ CNT agglomeration 
Fig. 8 illustrates ballistic limit speeds of seven specimens, after attempting six successful ballistic impacts, at various targets' angles with different volumes of CNT added into the epoxy resin including $0,0.1,0.3,0.5,0.7,1$, and 1.5 percent. In these single line graphs, $\mathrm{X}$-axis indicates percentages of CNT while Y-axis indicates ballistic limit in meter per second. In addition, Fig. 5 shows how various percentages of CNT increased fairly rapidly until $0.3 \% \mathrm{CNT}$, and then remained constant at the same level in $1 \%$ and $1.5 \%$ CNT.

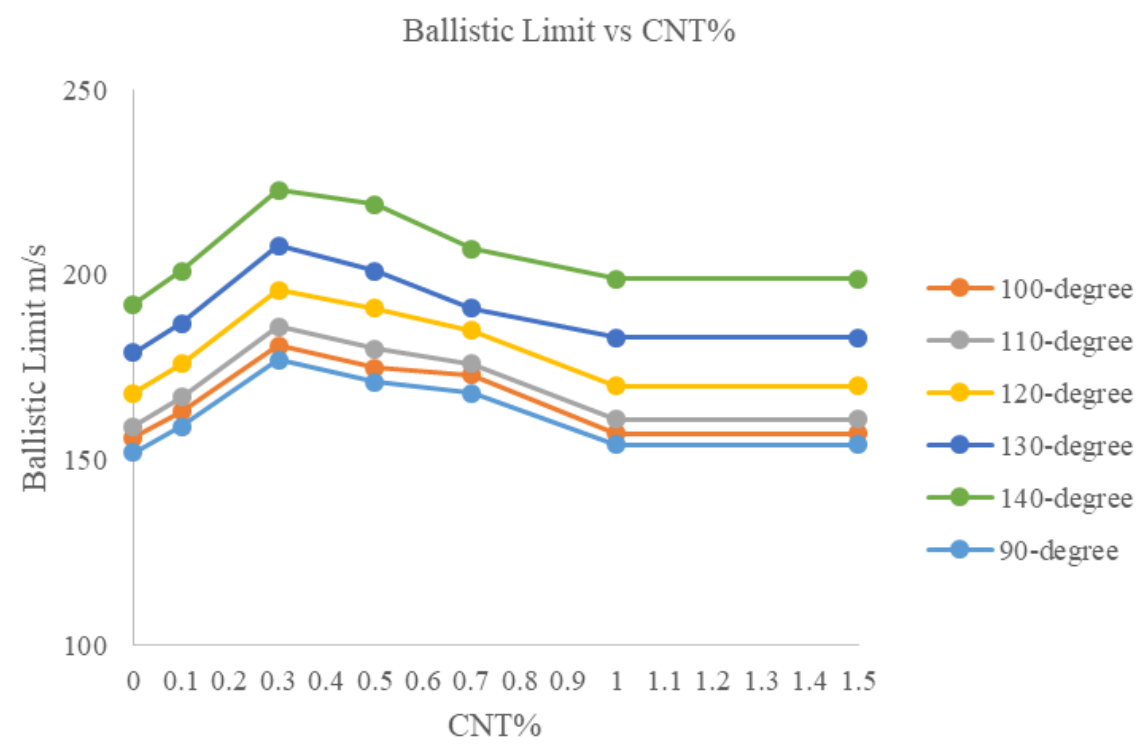

Fig. 8 Ballistic limit at angles with different amount of CNT

Ballistic limit speeds at 120 degrees of target differ from $168 \mathrm{~m} / \mathrm{s}$ to $196 \mathrm{~m} / \mathrm{s}$ in different percentages of CNT from 0 to 1.5\%. The Ballistic limit speed in the neat epoxy resin composite is $152 \mathrm{~m} / \mathrm{s}$. By adding CNT into the epoxy resin the speed resistance can be improved. In addition, the positive effect of the CNT inclusion into the epoxy resin is obviously illustrated that by adding $0.1 \%$ the speed is $176 \mathrm{~m} / \mathrm{s}$ while by adding $0.3 \%$ the speed is at maximum level from $196 \mathrm{~m} / \mathrm{s}$ to $223 \mathrm{~m} / \mathrm{s}$; it shows at least $18 \mathrm{~m} / \mathrm{s} \mathrm{improvement}$ of reinforcement technique. By increasing percentages of CNT from $0.3 \%$ to $0.5 \%$, which is the maximum point, the increasing of the speed can happen. By adding more than $0.3 \%$ CNT, the ballistic limit is gradually dropped from $196 \mathrm{~m} / \mathrm{s}$ to $185 \mathrm{~m} / \mathrm{s}$ at $0.7 \%$ of CNT. By increasing the amount of CNT the ballistic limit speed is decreased; by adding $1 \%$ of CNT, the speed rises from $166 \mathrm{~m} / \mathrm{s}$ to $199 \mathrm{~m} / \mathrm{s}$ and then the speed drops from $166 \mathrm{~m} / \mathrm{s}$ to $199 \mathrm{~m} / \mathrm{s}$. However, the speeds were still more than the neat epoxy by adding more than $0.3 \%$ of CNT. Moreover, there was a plateau of the ballistic limit between $154-207 \mathrm{~m} / \mathrm{s}$ by adding CNT from 1 to $1.5 \%$. In conclusion, the line graph displays the optimum percentage of CNT is $0.3 \%$ and by adding the CNT ballistic limit increasingly dropped. Nevertheless, it is apparent that the ballistic limit velocities increase with inclination and that the saturation limit for CNT content is $0.3 \%$. 
Fig. 9 shows ballistic limit speeds of seven specimens at 140 degrees of target with different volumes of CNT added into the epoxy resin including $0,0.1,0.3,0.5,0.7,1,1.5$ $\%$, and theoretical graph for the ballistic limit velocity. In this seven-line graphs, $\mathrm{X}$-axis indicates angles degree while $\mathrm{Y}$-axis indicates ballistic limit in meter per second. Increasing the angles can improve the body resistance against the impact, i.e. the highest ballistic limit velocity is for $0.3 \% \mathrm{CNT}$ at 140 degree and the lowest is for neat epoxy at 90 degree. The slanting protective layer can fabricate confirmation by an instrument, thickness of the plate disengaged by the cosecant of the point from impact course. Along these lines, the case for the occasion of a $100 \mathrm{~mm}$ piece of plate at a $40^{\circ}$ inclination from vertical with the shell course being parallel to the ground; according to $100 \mathrm{x} \mathrm{sec}(40)=$ $100 \times 1.56=156$. In the hindrance, by increasing the angles, the thickness is growing. Therefore, by saving the same mass due to increased thickness, the ballistic energy absorption can rise without increasing the mass. It means that, for example, at specimen thickness at $100 \mathrm{~mm}$, at 40 degrees the thickness can be achieved at 156 . In other words, the energy absorption can be increased at 56\%. However, the lowest ballistic limit of neat epoxy is higher than the theoretical one; this resistance happens due to the use of carbonKevlar fabric. The energy absorption of the ballistic impacts is directly proportional to their angles. Based on Equation 3, in Table 1, the greater the energy, the larger the angle (up to 90 degrees).

\section{Ballistic Limit vs. Degrees}

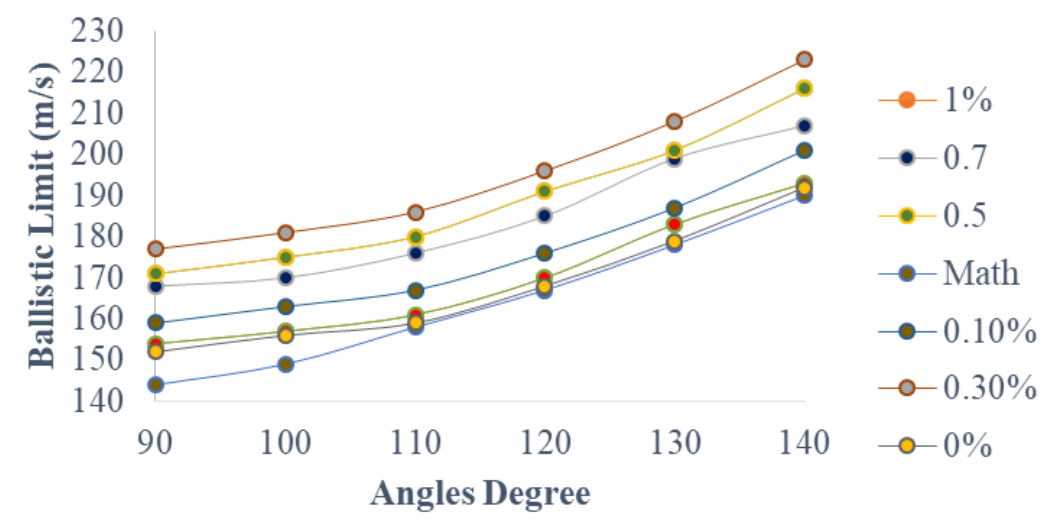

Fig. 9 Various specimens versus ballistic limit velocities

Table 1 ballistic limit by using TM5-855-1

\begin{tabular}{cc}
\hline Degree & Speed $(\mathrm{m} / \mathrm{s})$ \\
\hline 90 & 135 \\
100 & 137 \\
110 & 142 \\
120 & 151 \\
130 & 166 \\
140 & 192 \\
\hline
\end{tabular}


Fig. 9 illustrates and compares the amount of the ballistic limit energy absorption (in Joules) of seven carbon-Kevlar hybrid fabrics with various percentages of CNT added to the epoxy (from $0 \%$ to $1.5 \%$ ) impacted on six different angles (from 90 to 140 degrees).

\section{Energy Absorption vs Angles}

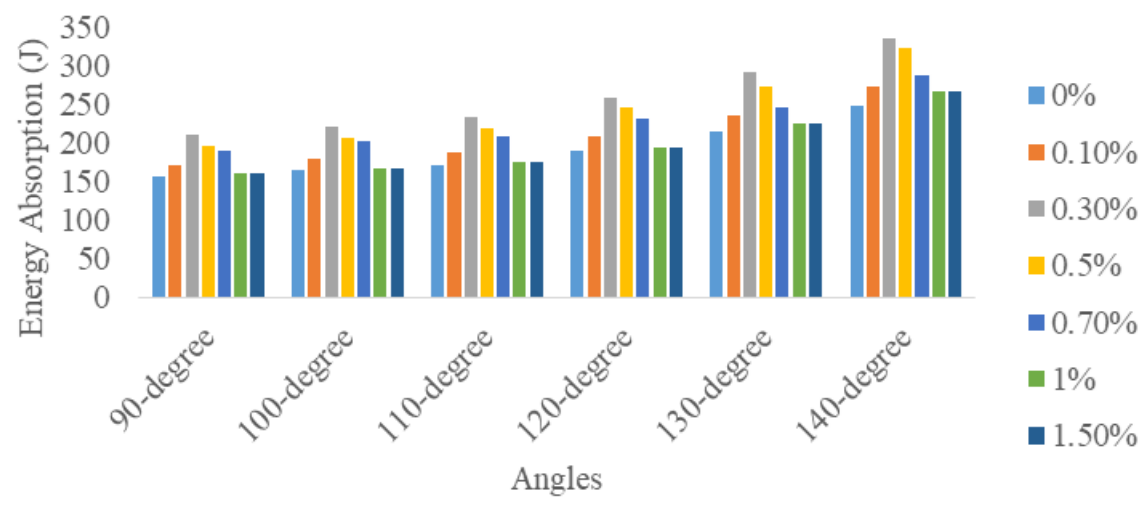

Fig. 9 Ballistic energy absorption of specimens at different angles

On the whole, the composite with inclusion of $0.3 \%$ CNT spent more energy on 140 degrees than $0.3 \%$ in the angles. All the composites with $0.3 \%$ CNT spent most of their energy absorption on different angles; whereas, the least amount of energy was spent on the neat epoxy in the 90 degrees compared to the neat epoxy in the 100 degrees also $1 \%$ and $1.5 \% \mathrm{CNT}$ in the 90 and 100 degrees. Furthermore, the most significant difference in the ballistic energy absorption between the two composites was in CNT percentage. Besides, in terms of angles, samples in the 140 degree spent about $250 \mathrm{~J}$ to more than $300 \mathrm{~J}$ on this as opposed to the $1 \%$ and $1.5 \%$ CNT in 90,100 , and 110 degrees at about 150 J. Similarly, the 130 degree ballistic energy absorption was higher on the $1 \%$ and $1.5 \%$ CNT in 130 degrees than the neat epoxy and $1 \%$ or $1.5 \%$ CNT in 90, 100, and 110 degrees (around $200 \mathrm{~J}$ and $210 \mathrm{~J}$, respectively). In the 120 degrees ballistic energy absorption on $0.3 \%$ CNT (just over $350 \mathrm{~J}$ ) was over $60 \%$ that of neat epoxy, $1 \%$ and $1.5 \%$ CNT in 90, 100, and 110 degrees, which was only $150 \mathrm{~J}$. On the other hand, the amount of the energy absorption depleted on the remaining samples was higher in with CNT epoxy. Above $250 \mathrm{~J}$ was depleted by the 120 , and 130 degrees on most samples, which was slightly more than the 100 degrees deplete about $225 \mathrm{~J}$. Neither of the 140 degrees depleted much on $0.3 \% \mathrm{CNT}$, which accounted for over $300 \mathrm{~J}$ of energy absorption also in $0.3 \% \mathrm{CNT}$ but approximately $220 \mathrm{~J}$ in the 90 degrees. High shear mixing to disperse homogeneously, the entanglement of CNTs produced by the agglomerates of CNTs caused by the intermolecular van der Waals force must be broken for homogenization, which can construct further fillers on obtainable surface area. A further intensification of similarity to composite material could be attained by a chemical functionalization of the carbon nanotube surface, through covalent or ionic bonds to the resin epoxy matrix. The bonds enable a stress transfer between the resin epoxy and CNTs, which leads to enhancing of the interfacial interactions. Furthermore, the covalent bonding is stronger as physical interactions anticipate a negligible influence on the ballistic 
impact performance of CNTs. Therefore, the reinforcement surface functionalization of CNTs accompanying noticeable dispersion of nanotubes in the matrix is the vital issue in developing CNT/resin epoxy composites. CNTs may result in tube breakage. The results illustrate some breakages transpire which signifies CNTs decrease by accumulating energy input. The rate at which CNTs is reduced abates as the material is dispersed and the tube separation increases. Consequently, tube breakage is not a serious problem and the aspect ratio of the tubes remains very high. Therefore, satisfactory dispersion can be achieved at the expense of an acceptable reduction in CNTs.

Fig. 10 illustrates the intact composite specimens (A) and impact C-scan proceeds before (B) and after (C) the ballistic impact test. Soon after that, the ultrasonic inspection shows that there are no types of delamination and voids on the samples before the ballistic impact occurrence in Fig. 10 (B). The contrast in tints and shades tone prevails because of the depth of the signal or deviation of the amplitude emitted under the sample, and can be helped with surface irregularities, which are inherent to the process. However, after conducting an oblique ballistic impact event, the extent of damage is clearly revealed in Fig. 10 (C).

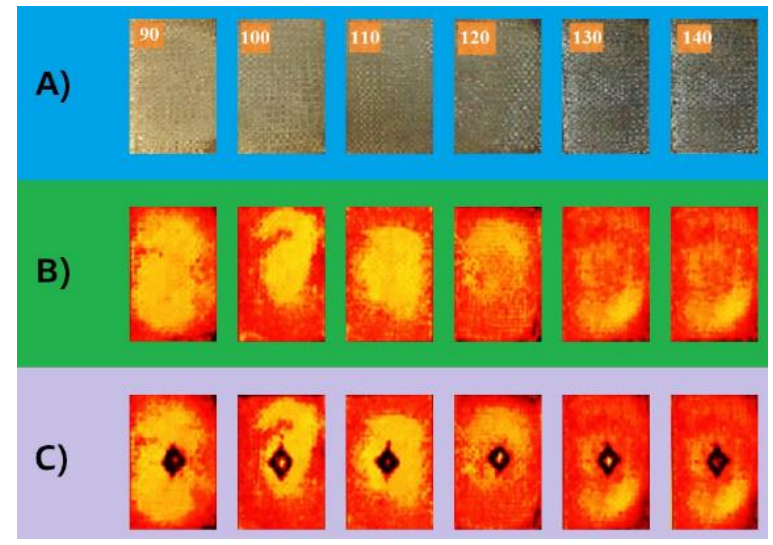

Fig. $10 \mathrm{C}$-scan inspections at $0.3 \% \mathrm{CNT}$

Fig. 11 displays in macroscopic scale the behavior of the composite plates in relation to the reinforced laminates at $0.3 \% \mathrm{CNT}$; it also shows total amount of the absorbed ballistic impact energy the specimen absorbed during the entire oblique impact test at 140 degrees. Therefore, the deformation of the laminates is observed as a repercussion of the beneficial combination of carbon fiber reinforcement with the CNT epoxy, which presents higher capability to disfigure without fracture. Moreover, it presents the types of damages occurring in the tested laminates on back. The observation called a small damage describes the initiating of delamination partially relating to fracture and it describes the delamination of various layers and the delamination of some layers. However, the specimen is completely penetrated by a high speed impact without complete fracture and the fractured specimens were impacted with adequate energy to clinch a complete failure. Accordingly, measuring the total ballistic impact energy absorbing capability is named penetration resistance. Correspondingly, the amount of the energy preliminary to the total penetration is related to the highest load, namely, the load the structure can bear before breaking utterly. Hence, 
maximum amount of the tolerable force by the material without even whole perforation is saturation ballistic impact energy [48-51]. To sum up, it can be clearly seen that resistance of reinforce matrix caused less fracture, which occurred despite the fact that the tearing of the fabrics matrix is still strong enough to trap the bullet.

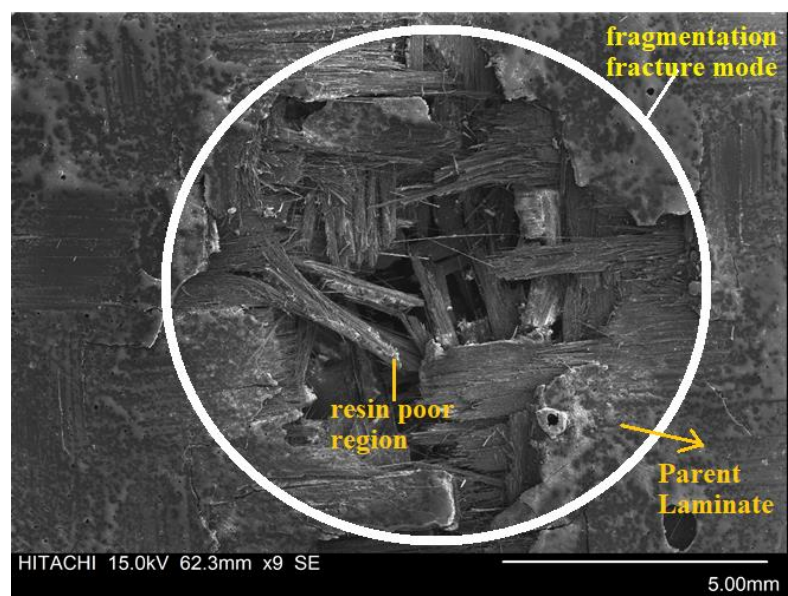

Fig. 11 Back face's specimens after impact at 140 degree with $0.3 \%$ CNT

\section{CONCLUSIONS}

Investigational studies were conducted experimentally on the ballistic impact behavior of the nanoparticle dispersed unidirectional laminate specimens Carbon Kevlar® Hybrid fabrics/epoxy composites with and without CNT. For comparison, studies were carried out on unidirectional laminate specimens Carbon Kevlar® Hybrid fabrics/epoxy with and without CNT. Damage and energy absorbing oblique ballistic impacts at different angles $(90,100,110,120,130$, and 140 degrees) for the different materials investigated are presented. Experimental data are given for the ballistic impact behavior of the seven types of specimens with CNTs $(0,0.1,0.3,0.5,0.7,1$, and $1.5 \%)$ examined. The specific observations are: firstly, the ballistic limit speed $\left(\mathrm{V}_{50}\right)$ can state comprehensibly that incorporating moderate loading of an optimized weight fraction of CNTs at $0.3 \%$ into Carbon Fiber / Kevlar ${ }^{\circledR}$ Hybrid fabric due to interlocking and Van der Waals forces improved the mechanical properties of the resultant nano-composite, accordingly were attributed to the CNTs being well dispersed within the resin epoxy; secondly, a higher amount of the CNTs (0.5-1.5 wt. \%) provided insufficient improvements in the impact energy absorbing properties, consequently at more than $0.3 \%$ of the CNTs significant reductions were technically recorded; thirdly, improvements in impact mechanical properties can be analytically achieved by increasing the angles of targets about $26 \%$, which is providing the most significant improvements in impact resistance due to rising the applied thickness of target analytically; lastly, CNTs reinforced composites exhibit more advantageously impact mechanical properties than neat epoxy. Moreover, CNTs normally exhibit elevated stiffness and extraordinary ballistic impact resistance, whose superior properties are predominantly 
attributed to the presence of robust $\mathrm{SP}^{2}$-bonded carbon-carbon lattice in their external shells; contrary to this, considering increasing the volume of CNTs, agglomeration can be occurred.

Acknowledgements: The paper is a part of the research done within the project code FRGS/1/2019/ STG07/UPM/02/10 and VOT No. 5540209. The authors would like to thank the Department of Aerospace Engineering, University Putra Malaysia (UPM) and the Ministry of Education, Malaysia.

\section{REFERENCES}

1. Ryerson, M.S., 2016, Planners take flight: integrating air transportation into planning education, Journal of Planning Education and Research, 36(4), pp. 427-439.

2. Scola, A., Eberling-Fux, N., Turenne, S., Ruiz, E., 2019, New liquid processing of oxideloxide 3D woven ceramic matrix composites, Journal of the American Ceramic Society, 102(6), pp. 3256-3268.

3. Clifton, S., Thimmappa, B.H.S., Selvam, R., Shivamurthy, B., 2020, Polymer nanocomposites for high-velocity impact applications-A review, Composites Communications, 17, pp. 72-86.

4. Chudoba, B., 2019, Generic aerospace vehicle design - knowledge utilization, In: Chudoba, B., Stability and Control of Conventional and Unconventional Aerospace Vehicle Configurations, Springer, Cham, pp. 19-46.

5. Bowman, C.L., Marien, T.V., Felder, J.L., 2018, Turbo-and hybrid-electrified aircraft propulsion for commercial transport, Proceedings of 2018 AIAA/IEEE Electric Aircraft Technologies Symposium, Cincinnati, Ohio, p. 4984.

6. Borgaonkar, A.V., Mandale, M.B., Potdar, S.B., 2018, Effect of changes in fiber orientations on modal density of fiberglass composite plates, Materials Today: Proceedings, 5(2), pp. 5783-5791.

7. Ravishankar, B., Nayak, S.K., Kader, M.A., 2019, Hybrid composites for automotive applications - A review, Journal of Reinforced Plastics and Composites, 38(18), pp. 835-845.

8. Keya, K.N., Kona, N.A., Koly, F.A., Maraz, K.M., Islam, M.N., Khan, R.A., 2019, Natural fiber reinforced polymer composites: history, types, advantages, and applications, Materials Engineering Research, 1(1), pp. 69-87.

9. Randjbaran E, Zahari R, Majid D.L., Sultan, M.T.H., Mazlan, N., 2018, Research paper in literature of increasing thickness by inclined target, Ely J Mat Sci Tech, 1(1), 104.

10. Randjbaran, E., Zahari, R., Majid, D.L., Sultan, M.T.H., Mazlan, N., 2017, Reasons of adding carbon nanotubes into composite systems-review paper, Mechanics and Mechanical Engineering, 21(3), pp. 549-568.

11. Valvano, S., Carrera, E., 2017, Multilayered plate elements with node-dependent kinematics for the analysis of composite and sandwich structures, Facta Universitatis,-Series Mechanical Engineering, 15(1), pp.1-30.

12. Duchene, P., Chaki, S., Ayadi, A., Krawczak, P., 2018, A review of non-destructive techniques used for mechanical damage assessment in polymer composites, Journal of materials science, 53(11), pp. 7915-7938.

13. Karnati, S.R., Agbo, P., Zhang, L., 2020, Applications of silica nanoparticles in glass/carbon fiber-reinforced epoxy nanocomposite, Composites Communications, 17, pp. 32-41.

14. Mylsamy, B., Palaniappan, S.K., Subramani, S.P., Pal, S.K., Sethuraman, B., 2020, Innovative characterization and mechanical properties of natural cellulosic Coccinia Indica fiber and its composites, Materials Testing, 62(1), pp. 61-67.

15. Vasudevan, A., Senthil Kumaran, S., Naresh, K., Velmurugan, R., 2020, Layer-wise damage prediction in carbon/Kevlar/S-glass/E-glass fibre reinforced epoxy hybrid composites under low-velocity impact loading using advanced 3D computed tomography, International Journal of Crashworthiness, 25(1), pp. 9-23.

16. Qu, J., Sun, Z., 2016, Strength behavior of shanghai clayey soil reinforced with wheat straw fibers, Geotechnical and Geological Engineering, 34(2), pp. 515-527.

17. Süsler, S., Kurtaran, H., Türkmen, H.S., Kazanc1, Z. Lopresto, V., 2020, An experimentally validated numerical method for investigating the air blast response of basalt composite plates, Mechanics of Advanced Materials and Structures, 27(6), pp. 441-454.

18. Pekbey, Y., Aslantaş, K., Yumak, N., 2017, Ballistic impact response of Kevlar Composites with filled epoxy matrix, Steel and Composite Structures, 22(4), pp. 191-200.

19. Wong, D.W., Zhang, H., Bilotti, E., Peijs, T., 2017, Interlaminar toughening of woven fabric carbon/epoxy composite laminates using hybrid aramid/phenoxy interleaves, Composites Part A: Applied Science and Manufacturing, 101, pp. 151-159. 
20. Nayak, S.Y., Satish, S.B., Sultan, M.T.H., Kini, C.R., Shenoy, K.R., Samant, R., Sarvade, P.P., Basri, A.A., Mustapha, F., 2020, Influence of fabric orientation and compression factor on the mechanical properties of $3 D$ E-glass reinforced epoxy composites, Journal of Materials Research and Technology, 9(4), pp. 8517-8527.

21. Randjbaran, E., Zahari, R., Majid, D.L., Sultan, M.T., Mazlan, N., 2018, Mechanical properties of disconnected multiwalled carbon nanotubes and carbon nanotube composites-a review paper, International Journal of Research-Granthaalayah, 6(6), pp. 212-225.

22. Yeter, E., 2019, Investigation of ballistic impact response of aluminum alloys hybridized with kevlar/epoxy composites, Politeknik Dergisi, 22(1), pp.219-227.

23. Wang, Z., Zhao, X. L., Xian, G., Wu, G., Raman, R. S., Al-Saadi, S., Haque, A., 2017, Long-term durability of basalt-and glass-fibre reinforced polymer (BFRP/GFRP) bars in seawater and sea sand concrete environment, Construction and Building Materials, 139, pp. 467-489.

24. Ning, F., Cong, W., Hu, Y., Wang, H., 2017, Additive manufacturing of carbon fiber-reinforced plastic composites using fused deposition modeling: Effects of process parameters on tensile properties, Journal of Composite Materials, 51(4), pp. 451-462.

25. Nayak, S.Y., Satish, S.B., Sultan, M.T.H., Kini, C.R., Shenoy, K.R., Samant, R., Sarvade, P.P., Basri, A.A., Mustapha, F., 2020, Influence of fabric orientation and compression factor on the mechanical properties of $3 D$ E-glass reinforced epoxy composites, Journal of Materials Research and Technology, 9(4), pp. 8517-8527.

26. Dhand, V., Mittal, G., Rhee, K. Y., Park, S. J., Hui, D., 2015, A short review on basalt fiber reinforced polymer composites, Composites Part B: Engineering, 73, pp. 166-180.

27. Prasad, P.R., Prakash, J.N., Manjunath, L.H., Reddy, P.V., 2020, Physical and wear properties of UHMWPE fabric reinforced epoxy composites, International Journal of Automotive and Mechanical Engineering, 17(1), pp. 7577-7586.

28. Shahbakhsh, S., Tohidlou, E., Khosravi, H., 2020, Influence of modified carbonate calcium nanoparticles on the mechanical properties of carbon fiber/epoxy composites, The Journal of The Textile Institute, 111(4), pp. 550-554.

29. Ahmad, F., Yuvaraj, N., Bajpai, P.K., 2020, Effect of reinforcement architecture on the macroscopic mechanical properties of fiberous polymer composites: A review, Polymer Composites, 41(6), pp. 2518-2534.

30. Rastogi, S., Verma, A., Singh, V.K., 2020, Experimental response of nonwoven waste cellulose fabricreinforced epoxy composites for high toughness and coating applications, Materials Performance and Characterization, 9(1), pp. 151-172.

31. Avrenli, K.A., Dempsey, B.J., 2017, A kinematic methodology to optimize the landing trajectory for the Boeing 737 jet undergoing total loss of thrust, Journal of Transportation Safety \& Security, 9(1), pp. 82-104.

32. Nešić, A., Čokorilo, O., Steiner, S., 2017, Aircraft Repair and Withdrawal Costs Generated by Bird Collision with the Windshield, Promet-Traffic\&Transportation, 29(6), pp. 623-629.

33. DeVault, T. L., Blackwell, B. F., Seamans, T. W., Belant, J. L., 2016, Identification of off airport interspecific avian hazards to aircraft, The Journal of Wildlife Management, 80(4), 746-752.

34. Mendoca, F.A., Keller, J., Wang, Y., 2017, Managing the risks: An analysis of bird strike reporting at Part 139 Airports in Indiana 2001-2014, Journal of Airline and Airport Management, 7(1), pp. 43-64.

35. Zekan, H.E., Haijun, X.U.A.N., Conger, B.A.I., Manli, S.O.N.G., Zhuoshen, Z.H.U., 2019. Containment of soft wall casing wrapped with Kevlar fabric, Chinese Journal of Aeronautics, 32(4), pp. 954-966.

36. Avrenli, K.A., Dempsey, B.J., 2014, Statistical analysis of aircraft-bird strikes resulting in engine failure, Transportation Research Record, 2449(1), pp. 14-23.

37. Avrenli, K.A., Dempsey, B.J., 2015, A kinematic approach to segmented-trajectory generation for the total loss of thrust emergency, Aviation, 19(3), pp. 138-149.

38. Qiu, J., Wang, D., Liu, C., Chen, L., Huang, H., Sun, Q., 2020, Dynamic response of bird strike on honeycombbased sandwich panels of composite leading edge, International Journal of Crashworthiness, pp. 1-14.

39. Liu, J., Liu, Z., Hou, N., 2019, An experimental and numerical study of bird strike on a 2024 aluminum double plate, Acta Mechanica Solida Sinica, 32(1), pp. 40-49.

40. Ribeiro, J.C., Damião, D., 2019, Analysis and evaluation of the risks of bird strikes in the international Guarulhos airport surroundings, Independent Journal of Management \& Production, 10(4), pp. 1193-1212.

41. Beffre, S.J., Washburn, B.E., 2020, Talking trash in the Big Apple: mitigating bird strikes near the North Shore Marine Transfer Station, Human-Wildlife Interactions, 14(1), pp. 55-63.

42. Cucinotta, F., Neri, P., Sfravara, F., Razionale, A., 2019, Composite sandwich impact response: experimental and numerical analysis, Frattura ed Integrità Strutturale, 13(47), pp. 367-382.

43. Randjbaran, E., Zahari, R., Jalil, N.A., Majid, D.L., 2014, Hybrid composite laminates reinforced with kevlar/carbon/glass woven fabrics for ballistic impact testing, The Scientific World Journal, 2014, 413753.

44. Sodhi, N.S., 2002, Competition in the air: birds versus aircraft, The Auk, 119(3), pp. 587-595. 
45. Pérez-Castán, J.A., Gómez Comendador, F., Cardenas-Soria, A.B., Janisch, D., Arnaldo Valdés, R.M., 2020, Identification, categorisation and gaps of safety indicators for u-space, Energies, 13, 608.

46. Dolbeer, R.A., 2006, Height distribution of birds recorded by collisions with civil aircraft, The Journal of Wildlife Management, 70(5), pp. 1345-1350.

47. Bartoli, M., Giorcelli, M., Rosso, C., Rovere, M., Jagdale, P., Tagliaferro, A., 2019, Influence of commercial biochar fillers on brittleness/ductility of epoxy resin composites, Applied Sciences, 9(15), 3109.

48. Blackwell, B.F., Wright, S.E., 2006, Collisions of red-tailed hawks (Buteo jamaicensis), turkey vultures (Cathartes aura), and black vultures (Coragyps atratus) with aircraft: implications for bird strike reduction, Journal of Raptor Research, 40(1), pp. 76-81.

49. Liu, J., Liu, Z., Hou, N., 2019, An experimental and numerical study of bird strike on a 2024 aluminum double plate, Acta Mechanica Solida Sinica, 32(1), pp. 40-49.

50. Conkling, T.J., Belant, J.L., DeVault, T.L., Martin, J.A., 2018, Impacts of biomass production at civil airports on grassland bird conservation and aviation strike risk, Ecological applications, 28(5), pp. 1168-1181.

51. Pfeiffer, M.B., Kougher, J.D., DeVault, T.L., 2018, Civil airports from a landscape perspective: a multi-scale approach with implications for reducing bird strikes, Landscape and Urban Planning, 179, pp. 38-45.

52. Rocha, R.J.B., Pina, L.M.P., Gomes, M., Sousa, J.P., 2020, Evaluation of impact resistant composites for aircraft cockpit, Materiales Compuestos, 4(1), pp. 1-9. 